\title{
Laser Assisted In Situ Keratomileusis (Lasik) Versus Trans Epithelial Photorefractive Keratectomy (T-Prk) In Astigmatic Patients
}

\author{
Mahar Safdar Ali Qasim, Muhammad Suhail Sarwar², Maher Mustansar Ali Qasim ${ }^{3}$ \\ ${ }^{1}$ Riphah International University, ${ }^{2}$ King Edward Medical University, Mayo Hospital, Lahore \\ ${ }^{3}$ Al-Razi Hospital, Rawalpindi
}

\begin{abstract}
Purpose: To compare the results of LASIK versus Trans Epithelial Photorefractive Keratectomy (T-PRK) in correcting astigmatic refractive error.

Study Design: Quasi experimental study.

Place and Duration of Study: Lahore Medicare Hospital from January to October 2018.

Methods: One hundred and twenty six eyes of 63 patients, age 18 to 35 years, either gender, presenting with astigmatism were enrolled in this study. Myopes with spherical equivalent (SE) $\leq-13.0$ diopter sphere (DS), hyperopes with SE $\leq+5.0$ DS and astigmatism $\geq 1.5 \mathrm{D}$ with visual acuity better or equal to 0.3 LogMAR were included. Astigmatic eyes with $<1.5 \mathrm{D}$ and with any other ocular pathology were excluded. Refractive status was assessed by Canon Autorefractor and Heine Retinoscope. Average reading of both methods was taken. Patients were divided into two groups (31: LASIK; 32: trans-PRK) by spin of a coin method. Refractive surgery was done in both groups. Data was analyzed by SPSS 20 . Normality of quantitative data was checked by Shapiro Wilk test. Mann Whitney-U test was used for non-parametric data. P-value $\leq 0.05$ was taken as significant.

Results: Mean age of the patients was $25.83 \pm 3.09$ years. The difference in residual sphere, amount of cylinder, axis of cylinder and CCT (central corneal thickness) after surgery in two groups was insignificant. $\mathrm{P}$ values were as follows; for sphere $p=0.85$, amount of cylinder $p=0.22$, axis of cylinder $P=0.46$ and CCT $p=0.07$.

Conclusion: Both techniques are equally good in correcting astigmatism ( $p=0.22)$. LASIK or T-PRK can be done alternatively in patients with astigmatism.
\end{abstract}

Key Words: LASIK, Trans epithelial PRK, Astigmatism.

How to Cite this Article: Qasim MSA, Sarwar MS, Qasim MMA. Laser Assisted in Situ Keratomileusis (Lasik) Versus Trans Epithelial Photorefractive Keratectomy (T-Prk) in Astigmatic Patients. Pak J Ophthalmol. 2022, 38 (1): 4-8.

Doi: $10.36351 /$ pjo.v38i1.1250

Correspondence: Mahar Safdar Ali Qasim

Riphah International University

Lahore - Pakistan

Email: safdarkemu@gmail.com

Received: April 06, 2021

Accepted: December 12, 2021

\section{INTRODUCTION}

The prevalence of astigmatic refractive error (defined as cylindrical error of more than 1.00 diopter) is between $15 \%$ and $34.3 \%$ worldwide. ${ }^{1}$ It is $37.00 \%$ in Pakistan. ${ }^{2}$ Large sample studies in Pakistan have also shown a significant number of corneal astigmatism. ${ }^{3}$ Moderate to high astigmatism has been a challenge for practitioner to correct it through refractive surgery. ${ }^{4}$ There are various factors that play role in the 
compromised results of refractive surgery including degree of astigmatism, axis of cylinder, and centration of surgical ablation profile. Chances of blur or haze formation after photorefractive keratectomy PRK as compared to laser assisted in situ keratomileusis (LASIK) can lead to regression of astigmatic error in long run ${ }^{5}$.

Refractive surgery is considered an advanced technique in the correction of refractive error. Some people prefer this for cosmesis. ${ }^{6}$ There are several procedures available for this purpose including Laser Assisted in situ keratomileusis (LASIK), Laser Assisted sub-epithelial keratomileusis (LASEK), transepithelial photorefractive keratectomy (T-PRK) and epithelial photorefractive keratectomy. ${ }^{7,8}$

In LASIK, corneal epithelial flap is formed and thickness of the flap can be variable depending upon the refractive requirement. After ablation of cornea the corneal flap is replaced on that cornea. ${ }^{9,10}$

Trans epithelial photo keratectomy (T-PRK) is another technique also used to correct myopia and hypermetropia. Trans-PRK is a comparatively newer method of the conventional PRK in which corneal epithelial is removed by an excimer laser rather than alcohol and manual scraping. This is assumed that it creates a smoother surface that allows rapid healing of epithelium which results in quicker visual recovery and minimum pain and all procedure is done after instillation of anesthesia drop to overcome blinking and patient's discomfort. After surgery contact lens is applied over corneal surface to assist regeneration of corneal epithelium and to minimize irritation and discomfort. $^{11-13}$.

As compared to the contact lenses especially (RGP) rigid gas permeable the vision quality is slightly less in laser corrective procedures as it needs more time to meet patient's expectations. Moreover prior to these procedures patient must discontinue using soft or rigid gas permeable lenses (one to four weeks) to stabilize corneal surface permitting accurate measurements. ${ }^{14}$

We designed this study to compare the results of LASIK and T-PRK. The idea was to find out which procedure has better results in our part of the world.

\section{METHODS}

This was an experimental (Quasi) study was conducted at Lahore-Medicare Hospital. From January 2018 to October 2018 after obtaining Ethical approval from University Ethical committee and Institutional review board of King Edward Medical University. Using nonprobability convenient sampling technique, 126 eyes of 63 patients, age $18-35$ years and presenting with astigmatism were included in the study. For the examination of anterior and posterior segments of the eye, retinal disorders and fundoscopy patients were dilated using $1.0 \%$ tropicamide eye drops and examination was done by an ophthalmologist. Visual acuity was taken by using LogMar visual acuity chart. Auto-refraction was done using Canon Autorefractometer. Retinoscopy was performed using Heine retinoscopy at $2 / 3$ of meter and average of both autorefractor reading and retinoscopy reading was taken. Topography was done using Schwind Amaris topography apparatus and planned for refractive surgery either LASIK or T-PRK using Schwind Amaris model 500E apparatus. After one month of surgery patient's visual status was recorded.

All cylindrical values were recorded in minus cylinder. If an individual came with plus cylindrical value, his cylindrical value was transposed to get minus cylinder. Individuals with minus cylindrical values were recorded with no change. Data was entered and analyzed by Statistical Package for the Social Scientist (SPSS 20.00). Quantitative Variables like refractive errors were presented as mean \pm standard deviation. Qualitative Variables like gender were presented as frequency and percentage. Assumption of data's normality was checked by Kolmogorov-Smirnov test and Shapiro Wilk test. All the variables were non-parametric as $p$-value was $<0.05$ (Table 1). Comparison of two groups LASIK and T-PRK was carried out by applying Mann Whitney $\mathrm{U}$ test. $\mathrm{P}$ value $\leq 0.05$ was taken as significant.

\section{RESULTS}

The Clinical characteristics are listed in Table $1 \& 2$. There was no significant difference between LASIK and T-PRK as regards Spherical, Cylindrical, Axis and corneal thickness values pre and post operatively. There were $55.60 \%$ females $(n=35)$ and $44.40 \%$ were males $(n=28)$. Mean age of the patients was $25.83 \pm$ 3.09 years. Further details are mentioned in Tables 1 , 2,3 and 4. 
Table 1 showed Mean values of Sphere, Cylinder and Axis in LASIK and T-PRK groups.

After refractive procedure, there were 44 and 61 eyes with Mean $\pm 0.25 \mathrm{D}$ and $\pm 0.50 \mathrm{D}$ residual cylinder in LASIK group. In T-PRK group 53 and 64 eyes had \pm 0.25 and $\pm 0.50 \mathrm{D}$ residual cylinder. Both groups did not show any major difference in residual refractive power.
Table 1: Descriptive Statistics of Residual Refractive Errors in Lasik vs. T-PRK.

\begin{tabular}{lcc}
\hline $\begin{array}{l}\text { Residual (Refractive } \\
\text { Errors) }\end{array}$ & $\begin{array}{c}\text { LASIK } \\
(\mathbf{n = 6 2}) \text { Mean }\end{array}$ & $\begin{array}{c}\text { T-PRK } \\
(\mathbf{n = 6 4}) \text { Mean }\end{array}$ \\
\hline Sphere & -0.08 & -0.11 \\
Cylinder & -0.22 & -0.17 \\
Axis & 31.84 & 30.11 \\
p value & \multicolumn{2}{c}{$=.220(\mathrm{P}>0.05)$} \\
\hline
\end{tabular}

Table 2: Descriptive Statics of Different Variables Vs Refractive Procedure.

\begin{tabular}{|c|c|c|c|c|c|c|c|c|}
\hline & & & Range & Minimum & Maximum & Mean & $\begin{array}{c}\text { Std. Error } \\
\text { of Mean }\end{array}$ & $\begin{array}{c}\text { Std. } \\
\text { Deviation }\end{array}$ \\
\hline \multirow{8}{*}{$\begin{array}{l}\text { LASIK } \\
(n=62 \\
\text { eyes })\end{array}$} & \multirow{5}{*}{ Pre-operative } & Sphere & 17.00 & -8.50 & 8.50 & -1.64 & 0.53 & 4.14 \\
\hline & & Cylinder & 1.25 & -2.75 & -1.50 & -1.92 & 0.04 & 0.30 \\
\hline & & Axis & 175.00 & 0.00 & 175.00 & 85.60 & 7.57 & 59.58 \\
\hline & & $\mathrm{CCT}$ & 104.00 & 460.00 & 564.00 & 547.06 & 1.66 & 13.09 \\
\hline & & Sphere & 1.75 & -0.75 & 1.00 & -0.08 & 0.05 & 0.42 \\
\hline & \multirow{3}{*}{ Post-operative } & Cylinder & 0.75 & -0.75 & 0.00 & -0.22 & 0.03 & 0.22 \\
\hline & & Axis & 177.00 & 0.00 & 177.00 & 31.84 & 6.28 & 49.45 \\
\hline & & $\mathrm{CCT}$ & 111.00 & 430.00 & 541.00 & 495.63 & 3.12 & 24.54 \\
\hline \multirow{8}{*}{$\begin{array}{l}\text { T-PRK } \\
(\mathrm{n}=64 \\
\text { eyes })\end{array}$} & \multirow{4}{*}{ Pre-operative } & Sphere & 17.00 & -9.50 & 7.50 & -2.19 & 0.51 & 4.08 \\
\hline & & Cylinder & 1.00 & -2.50 & -1.50 & -1.85 & 0.03 & 0.27 \\
\hline & & Axis & 175.00 & 0.00 & 175.00 & 75.16 & 6.70 & 53.61 \\
\hline & & $\mathrm{CCT}$ & 24.00 & 540.00 & 564.00 & 549.58 & 0.70 & 5.63 \\
\hline & \multirow{4}{*}{ Post-operative } & Sphere & 1.50 & -0.75 & 0.75 & -0.11 & 0.05 & 0.37 \\
\hline & & Cylinder & 0.50 & -0.50 & 0.00 & -0.17 & 0.02 & 0.19 \\
\hline & & Axis & 175.00 & 0.00 & 175.00 & 30.11 & 6.52 & 52.17 \\
\hline & & $\mathrm{CCT}$ & 126.00 & 410.00 & 536.00 & 500.22 & 3.45 & 27.61 \\
\hline
\end{tabular}

Table 3: Comparison of (CYLINDER) Post LASIK \&Post T-PRK Procedures.

\begin{tabular}{lccccc}
\hline \multirow{2}{*}{ Procedure } & \multicolumn{4}{c}{ Value of Cylinder After Surgery } & \\
& Cylinder & Frequency & Percent & Valid Percent & Cumulative Percent \\
\multirow{2}{*}{ LASIK } & -.75 & 1.00 & 1.60 & 1.60 & 1.60 \\
& -.50 & 17.00 & 27.40 & 27.40 & 29.00 \\
& -.25 & 18.00 & 29.00 & 29.00 & 58.10 \\
T-PRK & .00 & 26.00 & 41.90 & 41.90 & 100.00 \\
& -.50 & 11.00 & 17.20 & 17.20 & 17.20 \\
& -.25 & 22.00 & 34.40 & 34.40 & 51.60 \\
& .00 & 31.00 & 48.40 & 48.40 & 100.00 \\
\hline
\end{tabular}

Table 4: Comparison of Residual Cylinder in Lasik vs. T-PRK.

\begin{tabular}{llll}
\hline Null Hypothesis & \multicolumn{2}{c}{ Hypothesis Test Summary } \\
Test & Sig. & Decision \\
\hline $\begin{array}{l}\text { The Distribution of A_Cyl is the Same Across Categories } \\
\text { of Procedure }\end{array}$ & $\begin{array}{l}\text { Independent Sample Mann-Whitney } \\
\text { U Test }\end{array}$ & .22 & $\begin{array}{l}\text { Retain the Null } \\
\text { Hypothesis }\end{array}$ \\
\hline
\end{tabular}

There are no significant difference between LASIK and T-PRK groups as $\mathrm{p}$ value is $\geq 0.05$ ( $\mathrm{p}=$ 0.220).

\section{DISCUSSION}

This study showed the comparison of results of LASIK vs. T-PRK (in terms of cylindrical correction). 
Results showed no significant difference (equal visual results) as $p$ value was $>0.05$. A study conducted by American Society of RS showed that LASIK treated $98 \%$ of individuals within $\pm 0.50 \mathrm{D}$ Emmetropia and TPRK treated $96.4 \%$ of individuals within $\pm 0.50 \mathrm{D}$ Emmetropia. This study includes all type of spherocylindrical errors correction. Comparison of sphere, Axis of Cylinder and CCT (Central corneal Thickness) before and after refractive surgery in LASIK and T-PRK groups showed no significant difference as $\mathrm{p} \geq 0.05^{15}$

In contrast to our results, in another study eyes with low to moderate myopia were treated using different refractive procedures. T-PRK provided slightly better visual outcomes than LASIK or LASEK. In eyes with high myopia, T-PRK proved better than LASIK while Laser in situ keratomileusis was associated with the most major postoperative complications. $^{16}$

Variable results have been reported in literature regarding these two procedures. In another study both Trans-PRK and LASIK showed excellent efficacy, safety and predictability profiles. The results were comparable. $^{17}$

One year post operative follow up of T-PRK was reported by Luger et al. They showed that postoperative results of T-PRK were equivalent to those of femtosecond-assisted LASIK. They concluded that TPRK was efficacious and safe with a disadvantage that this procedure was associated with longer recovery time. $^{18}$

In low to middle income countries cost of the procedure is also a matter of concern for the patients. In a local study from Pakistan, although superior visual outcomes were reported with LASIK but patients satisfaction rate was higher in simple PRK due to the higher cost of LASIK. ${ }^{19}$ In T-PRK and LASIK, the difference in the cost is not very much. Hence, satisfaction level of the patient is related with the visual outcome as compared to the cost.

Some authors have also considered high order aberrations in their studies. In one study, the results showed that although the visual outcomes were slightly better in the PRK group, but aberrations showed better results in the LASIK group. ${ }^{20}$

Limitations of this study are that we did not consider the higher order aberrations due to the technological deficiencies and duration of followup was short. Patient satisfaction was also not taken into account.

\section{CONCLUSION}

Results of residual astigmatic sphero-cylindrical power, axis and central corneal thickness shows no significant difference in both refractive surgery procedures LASIK and T-PRK procedure. Therefore both surgical procedures are useful in astigmatism correction. This study suggests that LASIK and TPRK has same results in correcting astigmatism.

\section{Ethical Approval}

The study was approved by the Institutional review board/Ethical review board (ET/11/21).

\section{Conflict of Interest}

Authors declared no conflict of interest.

\section{REFRENCES}

1. Hassan H, Akbar F, Abbasi Y, Reza P, Haadi O, Mehdi K. Global and regional estimates of prevalence of refractive errors: Systemic overview and metaanalysis. J Curr Ophthalmol. 2018; 30 (1): 3-22.

2. Ayesha S, Hammad Z, Akram M, Zahid A. Prevalence of under-corrected refractive errors in adults aged 30 years and above in a rural population in Pakistan. NIH. 2015; 27 (1): 8-12.

3. Saba A, Anum I, Aun R, Quratulain Z. Frequency and amount and axis of astigmatism in subjects of Rawalpindi Pakistan. J Pak Med Assoc. 2013; 63 (11): 4-9.

4. Sugar A, Rapuano CJ, Culbertson WW, Huang D, Varley GA, Agapitos PJ, et al. Laser in situ keratomileusis for myopia and astigmatism: safety and efficacy: a report by the American Academy of Ophthalmology. Ophthalmology, 2002; 109 (1): 175187. Doi: 10.1016/s0161-6420(01)00966-6. PMID: 11772601.

5. Salomão MQ, Wilson SE. Femtosecond laser in laser in situ keratomileusis. J Cataract Refract Surg. 2010; 36 (6): 1024-32. PMID: 20494777.

6. Alió JL, Artola A, Claramonte PJ, Ayala MJ, Sánchez SP. Complications of photorefractive keratectomy for myopia: two year follow-up of 3000 cases. J Cataract Refract Surg. 1998; 24 (5): 619-626. doi: 10.1016/s0886-3350(98)80256-3. PMID: 9610444.

7. Spadea L, Sabetti L, D'Alessandri L, Balestrazzi E. Photorefractive keratectomy and LASIK for the correction of hyperopia: 2-year follow-up. J Refract Surg. 2006; 22: 131-136. 
8. Douglas KD. Excimer laser technology: New options coming to fruition, JCataract Refract Surg. 1997; 23 (10): 1429-1430. doi: 10.1016/S0886-3350(97)80001-6

9. Vengris M, Gabryte E, Aleknavicius A, Barkauskas M, Ruksenas O, Vaiceliunaite A, Danielius $\mathbf{R}$. Corneal shaping and ablation of transparent media by femtosecond pulses in deep ultraviolet range. J Cataract Refract Surg. 2010, 36: 1579-1587.

Doi: $10.1016 /$ j.jcrs.2010.06.027

10. Zheng Y, Zhou YH, Zhang J, Liu Q, Zhang L, Deng ZZ, et al. Comparison of Visual Outcomes After Femtosecond LASIK, Wave Front-Guided Femtosecond LASIK, and Femtosecond Lenticule Extraction. Cornea. 2016; 35 (8): 1057-1061.

11. Moussa S, Dexl A, Krall EM, Dietrich M, Arlt EM, Grabner G, et al. Comparison of short-term refractive surgery outcomes after wavefront-guided versus nonwavefront-guided LASIK. European journal of ophthalmology, 2016; 26 (6): 529-535.

12. Moshirfar M, Shah TJ, Skanchy DF, Linn SH, Kang P, Durrie DS. Comparison and analysis of FDA reported visual outcomes of the three latest platforms for LASIK: wavefront guided Visx iDesign, topography guided WaveLight Allegro Contoura, and topography guided Nidek EC-5000 CATz. Clin Ophthalmol. 2017; 11 (1): 135-147.

13. Nakamura Y, Hieda O, Yamamura K, Wakimasu K, Yokota I, Kinoshita S. Comparative Study of Sevenyear Outcomes Following Laser In Situ Keratomileusis with those of Trans-epithelial Photorefractive Keratectomy. Nippon Ganka Gakkai Zasshi, 2016; 120 (7): 487-493.

14. Nuzzi R, Tridico F. Comparison of visual outcomes, spectacles dependence and patient satisfaction of multifocal and accommodative intraocular lenses: innovative perspectives for maximal refractive-oriented cataract surgery. BMC Ophthalmology, 2017; 17 (1): 12.

15. Demill DL, Moshirfar M, Neuffer MC, Hsu M, Sikder S. A comparison of the American Society of Cataract and Refractive Surgery post-myopic LASI $\mathrm{K} / \mathrm{PRK}$ intraocular lens (IOL) calculator and the Ocular MD IOL calculator. Clin Ophthalmol. 2011; 5 (1): 1409-1414.
16. Faisal G, Ali A, Michael D. Laser in situ keratomileusis versus surface ablation: Visual outcomes and complications. J Cataract Refract Surg. 2007; 33 (12): 2041-2048. Doi: 10.1016/j.jcrs.2007.07.026

17. Gershoni A, Mimouni M, Livny E, Bahar I. ZLASIK and Trans-PRK for correction of high-grade myopia: safety, efficacy, predictability and clinical outcomes. Int Ophthalmol. 2019; 39: 753-763. doi.org/10.1007/s10792-018-0868-4

18. Michiel HA, Tobias Dipl-Ing E, Arba-Mosquera, Samuel. Myopia correction with transepithelial photorefractive keratectomy versus femtosecond-assisted laser in situ keratomileusis: Oneyear case-matched analysis, JCataract Refract Surg. 2016; 42 (11): 1579-1587.

Doi: $10.1016 /$ j.jcrs.2016.08.025

19. Hashmani N, Hashmani S, Ramesh P, Rajani H, Ahmed J, Kumar J, et al. A Comparison of Visual Outcomes and Patient Satisfaction Between Photorefractive Keratectomy and Femtosecond LaserAssisted In Situ Keratomileusis. Cureus, 2017; 9 (9): e1641. doi:10.7759/cureus.1641

20. Sajjadi V, Ghoreishi M, Jafarzadehpour E. Refractive and Aberration Outcomes after Customized Photorefractive Keratectomy in Comparison with Customized Femtosecond Laser. Med Hypothesis Discov Innov Ophthalmol. 2015; 4 (4): 136-141. PMID: 27800501; PMCID: PMC5087100.

\section{Authors' Designation and Contribution}

Mahar Safdar Ali Qasim; Assistant Professor: Concepts, Design, Literature Search, Data Acquisition, Data Analyis, Statistical Analysis, Manuscript Preparation, Manuscript Editing, Manuscript Review.

Muhamnmad Suhail Sarwar; Principal and Head of Department: Design, Literature Search, Data Acquisition, Data Analyis, Statistical Analysis, Manuscript Review.

Maher Mustansar Ali Qasim; Optometrist: Literature Search, Data Acquisition, Data Analyis, Manuscript Preparation, Manuscript Review.

\section{DISCLAIMER}

It is testify that this is my M.Phil. research product and that was conducted as a part of degree requirment in King Edward Medical University (KEMU) and data was collected at Lahore Medicare Hospital, Lahore.

All the authors were present in the said place during the conductio of study.

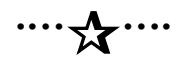

